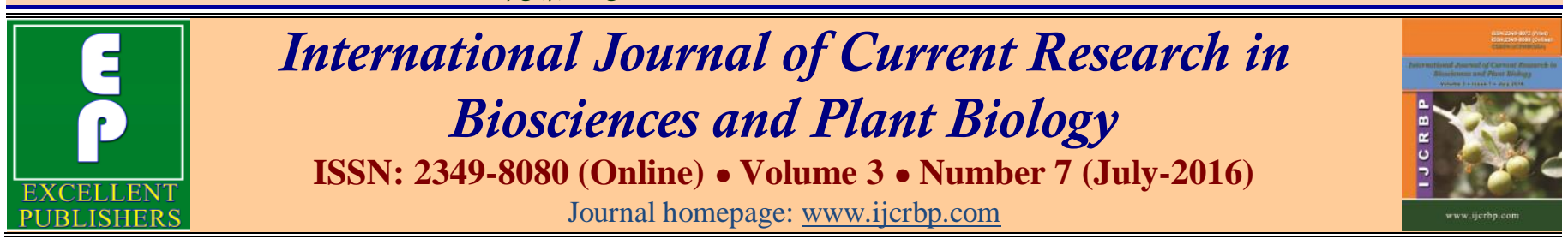

Original Research Article

doi: http://dx.doi.org/10.20546/ijcrbp.2016.307.001

\title{
Clinical Profile and Risk Factors of Acute Coronary Syndrome in Cardiac Care Unit Patients at Elobied Hospital - West Sudan
}

\author{
Khalid Mohamed Eisa Eltalib ${ }^{*}$ and AbdelSalam Mohamed Hamad Elfaki ${ }^{2}$ \\ $1 \& 2$ MD Medicine, Faculty of Medicine and Health Sciences, University of Kordofan, Sudan \\ *Corresponding author.
}

\begin{abstract}
In the presence of increasing risk factors like hypertension, diabetes mellitus, and obesity in our community, acute coronary syndrome appears to be a real health problem. This study aimed to determine the clinical profile and risk factors of acute coronary syndrome among patients admitted to Cardiac Care Unit at Elobied Teaching hospital. This is a hospital-based retrospective study done by reviewing records of 84 patients who were admitted to the Cardiac Care Unit with the clinical diagnosis of acute coronary syndrome from the period July 2014 to November 2015. The data were obtained through well-designed data sheet including age, gender, and residence. Clinical presentation, risk factors like hypertension diabetes and cigarette smoking. The data sheet also included ECG findings, complications and outcome of the patients. The data were analyzed using SPSS version 14. More than half of patients were above 60 years (65\%). More than half of patients were males (56\%). Chest pain was the predominant presenting complaint (98\%). More than half of patients were hypertensive (57\%) while one third were diabetic (33\%). One third of patients were smokers. Troponin was positive in $63 \%$ of patients, ECG was abnormal in $68 \%$ of patients and $61 \%$ of the patients were referred for coronary angiography. This study showed that hypertension, diabetes mellitus and smoking are the major risk factors for acute coronary syndrome, early detection and management of hypertension and diabetes are indicated. Establishment of catheter laboratory in our setting should be given a priority.
\end{abstract}

\section{Introduction}

Coronary artery disease (CAD) is the leading cause of mortality and morbidity in the world and acute coronary syndromes (ACS), which encompass unstable angina (UA), non-ST-segment elevation myocardial infarction (NSTEMI) and ST-segment elevation myocardial infarction (STEMI), are the commonest causes of mortality in patients with CAD.

Risk factors for ACS include older age, previous atheromatous cardiovascular disease, diabetes, smoking, hypertension, hypercholesterolemia, male sex, and a

\author{
Article Info \\ Accepted: 07June 2016 \\ Available Online: 06 July 2016 \\ Key w o r d s \\ Acute coronary syndrome \\ Non-ST elevation myocardial \\ infarction \\ ST elevation myocardial infarction \\ Unstable angina
}

family history of premature ischemic heart disease. Acute coronary syndrome often causes severe chest pain or discomfort. It is a medical emergency that requires prompt diagnosis and care. Treatment goals include: improving blood flow, treating complications, and preventing future problems.

Elobied hospital is 750 -bed tertiary hospital. It has a large catchment area offering services to patients from North Kordofan as well as patients coming from west and south Kordofan states. The Cardiac Care Unit is well-equipped with 9 beds and well trained doctors and nursing staff. 
This study aimed to determine the clinical profile and risk factors of acute coronary syndrome among patients admitted to Cardiac Care Unit at Elobied teaching hospital.

\section{Patients and methods}

This is a hospital-based retrospective study done by reviewing records of 84 patients who were admitted to the Cardiac Care Unit with the clinical diagnosis of acute coronary syndrome from the period July 2014 to November 2015. The data were obtained through welldesigned data sheet including age, gender, and residence. Clinical presentation, risk factors like hypertension diabetes and cigarette smoking. The data sheet also included ECG findings, complications and outcome of the patients. The data were analyzed using SPSS version 14.

\section{Results}

Eighty four patients admitted to the CCU with clinical diagnosis of acute coronary syndrome were included in this study. More than half of the patients were in age group above 60 years $(65 \%)$. More than half of patients were males $(56 \%)$. The commonest presenting symptom was chest pain $(98 \%)$, followed by shortness of breath $(30 \%)$, and sweating (17\%) (Table 1).

Table 1. Main presenting symptoms of acute coronary syndrome in Cardiac Care Unit patients at Elobied Hospital, West Sudan.

\begin{tabular}{lll}
\hline Symptom & Frequency & Percent \\
\hline Chest pain & 82 & $98 \%$ \\
Shortness of breath & 30 & $36 \%$ \\
Palpitation & 13 & $15 \%$ \\
Sweating & 14 & $17 \%$ \\
\hline
\end{tabular}

More than half of patients were hypertensive (57\%) while one third of them were diabetic (33\%). One third of patients were smokers. Troponin was positive in $63 \%$ of patients, ECG was normal in 33\% of patients, while $44 \%$ of patients had ST segment elevation, and $15 \%$ had ST segment depression. T wave inversion was found in $4 \%$ of our patients. Left bundle branch block (LBBB) was also found in $4 \%$ of patients (Table 2).

Congestive heart failure was diagnosed in 15 patients (17.8\%), while one patient developed stroke (1.2\%). Only one patient developed mechanical complication in form of Ventricular septal defect (VSD) (Table 3).
Table 2. ECG changes in patients with acute coronary syndrome in Cardiac Care Unite, Elobied Hospital, West Sudan.

\begin{tabular}{lll}
\hline ECG changes & Frequency & Percent \\
\hline Normal ECG findings & 27 & $32 \%$ \\
ST segment depression & 14 & $17 \%$ \\
T wave inversion & 03 & $04 \%$ \\
ST segment elevation & 37 & $45 \%$ \\
Left Bundle Branch Block (LBBB) & 03 & $04 \%$ \\
Total & $\mathbf{8 4}$ & $\mathbf{1 0 0 \%}$ \\
\hline
\end{tabular}

Table 3. Complications of acute coronary syndrome in Cardiac Care Unit patients at Elobied Hospital, West Sudan.

\begin{tabular}{lll}
\hline Complication & Frequency & Percent \\
\hline No complication & 67 & $80 \%$ \\
Heart failure & 15 & $18 \%$ \\
Ventricular Septal Defect (VSD) & 01 & $01 \%$ \\
Stroke & 01 & $01 \%$ \\
\hline
\end{tabular}

\section{Discussion}

In this hospital-based retrospective study, records of 84 patients who were admitted to the cardiac care unit with the clinical diagnosis of acute coronary syndrome were reviewed. Sixty five percent of patients were above 60 years of age. This finding was different from reports from South Africa (Ranjith et al., 2005). Males constituted more than half of patients admitted with ACS (56\%), while reports from Saudi Arabia showed male predominance of $77 \%$ (Hersi et al., 2013).

In this study hypertension was found in $57 \%$ of patients, $33 \%$ of patients were diabetics, while One third of patients were smokers. In study done by Chahare et al. (2015), hypertension was found in $75 \%$ of patients, smoking was found in $70 \%$, while diabetes mellitus was found in $71 \%$. So it is obvious that both diabetes mellitus and cigarette smoking as risks factors for ACS were less recognized in our study compared with previously mentioned study. In a study from Saudi Arabia, hypertension and smoking were reported in $31.8 \%$ and $25.2 \%$ respectively with low incidence of hypertension and smoking compared with our study (Al-Murayeh et al., 2012).

Chest pain was the commonest presenting symptom (98\%), followed by shortness of breath (30\%) and sweating (14\%) (Table 1). The incidence of chest pain was similar to reports by Singh et al but the percentage 
of sweating and breathlessness were higher than ours (75\% and 60\% respectively) (Singh et al., 2013). STMI was diagnosed in $44 \%$ of patients, a result which more or less similar to reports from Saudi Arabia in which STMI was reported in $41.5 \%$ (Alhabib et al., 2011).

In this study the common complication was heart failure which found in 15 patients (18\%), while two patients developed stroke and ventricular septal defect (VSD), one in each. Comparing our results with study from India, cardiac arrhythmias were the commonest complication $(60 \%)$ followed by cardiac failure $(35 \%)$ (Yadav et al., 2010).

\section{Conclusion}

This study showed that hypertension, diabetes mellitus and smoking are the major risk factors for acute coronary syndrome, early detection and management of hypertension and diabetes are indicated. Establishment of catheter laboratory in our setting should be given a priority.

\section{Conflict of interest statement}

Authors declare that they have no conflict of interest.

\section{References}

Alhabib, K. F., Hersi, A., Alfaleh, H., Alnemer, K., AlSaif, S., Taraben, A., Kashour, T., Bakheet, A., Al Qarni, A.,
Soomro, T., Malik, A., Ahmed, W. H., Abuosa, A. M., Butt, M. A., AlMurayeh, M. A., Al Zaidi, A., Hussein, G. A., Balghith, M. A., Abu-Ghazala, T., 2011. Baseline characteristics, management practices, and in-hospital outcomes of patients with acute coronary syndrome: Results of the Saudi project for assessment of coronary events (SPACE) registry. J. Saudi Heart Assoc. 23(4), 233-239.

Al-Murayeh, M. A., Al-Masswary, A. A., Dardir, M. D., Moselhy, M. S., Youssef, A. A., 2012. Clinical presentation and short-term outcome of acute coronary syndrome in native young Saudi population. J. Saudi Heart Assoc. 24(3), 169-175.

Chahare, V. W., Ray, T., Bhattacharya, C., Wankar, Ad., 2015. Clinical profile of patients with acute coronary syndrome with special reference to diabetes mellitus. Int. J. Res. Med. Sci. 3(4), 849-859.

Hersi, A., Al-Habib, K., Al-Faleh, H., Al-Nemer, K., Alsaif, S., Taraben, A., Kashour, T., Abuosa, A. M., Al-Murayeh, M. A., 2013. Gender inequality in the clinical outcomes of equally treated acute coronary syndrome patients in Saudi Arabia. Ann. Saudi Med. 33(4), 339-346.

Ranjith, N., Pegoraro, R. J., NaIdoo, D. P., 2005. Demographic data and outcome of acute coronary syndrome in the South African Asian Indian population. Cardiovasc. J. South Afr. 16(1), 48-54.

Singh, P. S., Singh, G., Singh, S. K., 2013. Clinical profile and risk factors in acute coronary syndrome. J. Ind. Acad. Clin. Med. 14(2), 130-132.

Yadav, P., Joseph, D., Joseph, D., Joshi, P., Sakhi, P., Jha, R.K., Gupta, J., 2010. Clinical profile and risk factors in acute coronary syndrome. Nat. J. Commun. Med. 1(2), $150-153$.

\section{How to cite this article:}

Eisa Eltalib, K. M., Hamad Elfaki, A. M., 2016. Clinical profile and risk factors of acute coronary syndrome in cardiac care unit patients at Elobied Hospital - West Sudan. Int. J. Curr. Res. Biosci. Plant Biol. 3(7), 1-3. doi: http://dx.doi.org/10.20546/ijcrbp.2016.307.001 